The New Woman. Contributions of socialist feminists to the moral and political debates in the 21st Century

\title{
La Mujer nueva. Aportaciones de las feministas socialistas a los debates morales y políticos del siglo XXI
}

\author{
Eva Palomo Cermeño \\ Universidad Rey Juan Carlos \\ eva.palomo@urjc.es \\ María Ávila Bravo-Villasante \\ Universidad Rey Juan Carlos \\ maria.avila@urjc.es
}

DOI: https://doi.org/10.15366/bp2021.27.011

Bajo Palabra. II Época. № 27. Pgs: 213-230 
Recibido: 30/03/2020

Aprobado: 07/05/2021

\section{Resumen}

Las ideas en torno a la Mujer nueva marcaron los debates acerca del género y la clase, el feminismo y el socialismo, durante el siglo XIX y principios del XX. En el presente trabajo se revisan y analizan las aportaciones de diversas autoras pertenecientes a la tradición del feminismo socialista, como son Anna Wheeler, Clara Zetkin, Alexandra Kollontai o Sylvia Pankhurst. Se trata de establecer un diálogo presente-pasado en torno a los retos morales y políticos que presentan al feminismo las sociedades contemporáneas.

Palabras clave: Mujer-nueva, feminismo, socialismo, interseccionalidad, filosofia-moral-politica.

\section{Abstract}

During the $19^{\text {th }}$ Century and the early $20^{\text {th }}$ gender-class and feminism and socialism debates were influenced by the ideas developed around the New Woman. The contributions of different authors from the socialist feminist tradition such as Anna Wheeler, Clara Zetkin, Alexandra Kollontai or Sylvia Pankhurst are reviewed and analyzed. In this paper a dialogue between the present and the past is established regarding the moral and political challenges faced by feminism in contemporary societies.

Keywords: New-Woman, Feminism, Socialism, Intersectionality, Moral-Political-Philosophy. 


\section{Introducción}

CuANdo a PRINCIPIOS Del siglo XX Alejandra Kollontai vaticina el advenimiento de la "mujer nueva", anuncia la llegada de un nuevo arquetipo que ya estaba presente en las teorías feministas socialistas. La "mujer nueva" es un tipo psicológico, "un tipo de heroína que trae sus propias exigencias en relación con la vida, que afirma su personalidad, que protesta contra la múltiple esclavitud de la mujer bajo el Estado, la familia, la sociedad, una clase de mujer que lucha por sus derechos y que representa su propio sexo" 1 .

Este artículo pretende establecer un diálogo con las autoras feministas socialistas con el objetivo de indagar cómo abordarían las mujeres nuevas del siglo XIX y principios del XX los actuales debates éticos que incumben al feminismo. Somos conscientes de que las propuestas teóricas planteadas por las autoras expuestas son elaboradas en un escenario diferente al nuestro. No obstante, la riqueza de sus argumentos, la novedad de sus teorías y la perspicacia de sus conceptualizaciones permite que indaguemos en sus propuestas y de este modo, arrojar luz sobre algunos de los debates no resueltos. Muchas de ellas, han sido recogidas en la obra de Mary Ellen Waithe, History of Women Philosophers, considerada por la propia autora como un proyecto abierto en el que pueden tener cabida muchas mujeres en el campo de la filosofía política sobre las que aún siguen investigando las filósofas e historiadoras. ${ }^{2}$

En un primer momento, abordaremos un tema de gran actualidad ¿Es posible la igualdad entre mujeres y hombres en el sistema de producción capitalista? En 1825 una de estas mujeres nuevas Anna D. Wheeler, afirma rotundamente que en un sistema tal, es imposible la igualdad.

El segundo momento de nuestra propuesta pretende poner de manifiesto la realidad calidoscópica del feminismo. En ocasiones la enumeración rapsódica de olas feministas tiende a una simplificación excesiva de las posturas internas, anulando los ricos metadebates que se han sucedido. Esta simplificación ofrece una imagen monolítica del feminismo que ya fue rechazada en el siglo XIX por Clara Zetkin. La autora, puso de manifiesto que los intereses de las mujeres no son homogéneos.

\footnotetext{
Kollontai, Alejandra. Marxismo y Revolución Sexual. Madrid, Castellote, 1976, p. 65.

2 Waithe, M. Ellen. History of Women Philosophers. Vol. III. Dordrecht: Kluwer Academic Publishers, 1991.
} 
En la tercera parte del artículo tomaremos el testigo de Kollontai y abordaremos la prostitución de mujeres y la crisis sexual. ¿Podemos seguir hablando de revolución de las costumbres o estamos ante una torpe, lenta y, a veces, reaccionaria evolución?

Para finalizar, analizaremos las aportaciones de la sufragista y socialista Sylvia Pankhurst a los debates en torno al género, la clase y la raza. La obra de esta autora de principios del siglo XX nos muestra algunas claves fundamentales para comprender cómo el tan actual concepto de interseccionalidad cuenta con antecedentes de interés dentro de la genealogía feminista, generalmente poco estudiada por razones androcéntricas. Así mismo, con la presente revisión se pretende poner en valor unas aportaciones fundamentales para la historia de las ideas y la filosofía moral y política.

\section{No hay igualdad en el sistema de producción capitalista: Anna D. Wheeler y William Thompson.}

LA CRISIS ECONÓMICA GLOBAL DE 2007 y, sobre todo, las huelgas feministas que se vienen secundando desde 2017, han puesto en el centro del debate social la pregunta por la posibilidad de la igualdad en el sistema de producción capitalista. Autoras como Cinzia Arruza, Tithi Bhattacharya y Nancy Fraser en Feminism for the 99\% se manifiestan contra esta posibilidad. Charlene Carruthers, autora de Unapologetic: A Black, Queer, and Feminist Mandate for Radical Movements, afirmaba en una entrevista concedida al diario El País, que "Acabar con el capitalismo es un asunto feminista." 3 En estas autoras se pone de manifiesto la tesis que Wheeler nos anunció hace dos siglos: no es posible la igualdad en el sistema de producción capitalista.

En 1825, Anna Wheeler y William Thompson publican La demanda de la mitad de la raza humana, las mujeres contra la pretensión de la otra mitad los hombres, de mantenerlas en la esclavitud política y, en consecuencia, civily doméstica. La obra surge en respuesta a la obra de James Mill, Sobre el gobierno, publicada como suplemento en la Enciclopedia Británica en 1820. En esta obra, James Mill desestima el derecho al voto de las mujeres al considerar que sus intereses se encuentran incluidos en los de sus padres o maridos. La situación legal de las mujeres queda asimilada a la de los niños pequeños, con una clara diferencia: los niños, podrán hacer valer sus derechos una vez que se conviertan en adultos.

\footnotetext{
${ }^{3}$ Mars, Amanda, "Charlene A. Carruthers. 'Acabar con el capitalismo es un asunto feminista." El País, 15 de diciembre de 2019.
} 
Aunque la motivación inicial de La demanda es poner al descubierto la errónea inferencia lógica realizada por James Mill, la obra transciende sus intenciones iniciales, convirtiéndose en un exhaustivo análisis de la situación de las mujeres en la Gran Bretańa de principios de siglo XIX. Los valores ilustrados que sustentan las emergentes sociedades burguesas habían desplazado a la religión y a la tradición como factores legitimadores de la servidumbre o inferioridad de las mujeres. Wheeler y Thompson ponen de manifiesto como el nuevo orden, legitima la subordinación y la inferioridad de las mujeres en su naturaleza diferente y complementaria.

La demanda, abordará algunos de los temas centrales del feminismo ilustrado: matrimonio, derecho a la propiedad, empleo, educación, prostitución... y lo hace bajo el auspicio de la nueva filosofía moral. Sus reflexiones incluyen, además, una crítica al capitalismo como sistema económico que impide la verdadera igualdad entre los sexos y su apuesta por el cooperativismo.

En la carta introductoria a $L a$ demanda, Wheeler manifiesta que es necesario un nuevo orden social en el que coincidan el deber y el interés. Sólo bajo este nuevo orden de cooperación mutua entre personas será posible una igualdad efectiva entre mujeres y hombres. Bajo la competición individual, esto es, bajo el orden capitalista, todo se rige por la fuerza, mientras que, en el nuevo orden social "la utilidad de la fuerza física superior del hombre para la felicidad general se contrapesa con la particular facultad de las mujeres para parir y criar nińos." ${ }^{4}$

Al final de la obra, Wheeler y Thompson retoman la cuestión del cooperativismo señalando que es imposible la igualdad en el sistema de acumulación individual de riqueza:

"Bajo el sistema de competición individual y de acumulación individual de riqueza, siempre estaréis sujetas a la contingencia de la miseria por la muerte de productor activo de la familia, así como a la injusticia que ocasionalmente pueda derivarse del abuso doméstico de la fuerza superior y de la influencia, contra el que ninguna ley puede protegeros completamente". ${ }^{5}$

Un sistema de trabajo basado en la cooperación mutua aseguraría la igualdad entre hombres y mujeres, eliminando todas aquellas desigualdades que, ni leyes civiles, penales o morales, han podido modificar. Es más, el nuevo orden proporcionará, también, soluciones a la desigualdad natural. Cuando se trabaja por el bien común, esto es, una vez eliminada la propiedad individual y la competitividad,

\footnotetext{
${ }_{4}^{4}$ Thompson, William y Wheeler, Anna. La demanda de la mitad de la raza humana, las mujeres contra la pretensión de la otra mitad los hombres, de mantenerlas en la esclavitud política y, en consecuencia, civil y doméstica. Granada, Comares, 2000, p. 51.

${ }^{5}$ Ibid., p. 232.
} 
todos los talentos y facultades — sean fruto de la educación diferenciada, sean por constitución - son igualmente valorados. Nińos y niñas serán educados y sostenidos por toda la comunidad dejando de depender de la generosidad (o tacañería) de sus padres.

Una parte fundamental de La demanda está destinada a denunciar la esclavitud de las mujeres, especialmente de las mujeres casadas. Su sumisión era el precio que tenían que pagar por tener acceso a riquezas o a un plato de comida. La miseria en caso de abandono o viudedad planeaba sobre sus vidas y sobre la de sus hijos e hijas. Bajo la cooperación mutua, las mujeres dejarán de depender de los hombres, la propiedad sería común y todos poseerán las mismas riquezas. El nuevo régimen exime a las mujeres de la esclavitud.

El contrato de esclavitud no tiene cabida en un sistema de estas características, "el hombre no posee más riqueza que la mujer con la que comprar su persona para su uso animal durante algunos años." ${ }^{6}$ Los hombres, deberán aplicarse las recomendaciones que Rousseau realizaba a las mujeres, y entrenarse en el arte de agradar, pues tendrán que aprender a merecer el amor. Siendo la riqueza la misma, siendo la propiedad común y reducida la fuerza física de los hombres a su justo nivel de utilidad, el único modo de obtener gratificación sexual será por la libre voluntad de las mujeres.

En el cooperativismo, tampoco tiene cabida el sistema de dominación patriarcal basado en la doble moral. Si los hombres castigan las indiscreciones de las mujeres deben sancionar, también, las suyas propias, y si la felicidad común así lo requiere, deberán ser reprimidas en ambos sexos. La prostitución quedará erradicada, fuera de un sistema moral corrupto no se puede sostener. Además, al estar las mujeres completamente abastecidas, como cualquier miembro de la comunidad, no se sentirán en la necesidad (o vanidad) de vender el uso de su persona.

"El amor de las mujeres debe ganarse, debe merecerse, y no como ahora, comprarse o exigirse: no se prostituirá con descreídos de corazón que, primero robarían la joya, y después matarían con su desprecio a su inocente y confiada propietaria. ¡Estos hombres, en esta Asociación podrán amarse a sí mismos! ¡Una forma de amor en la que no encontrarán rivales que los molesten!" 7

Por último, en el nuevo sistema de cooperación mutua mujeres y hombres recibirán una educación global e igualitaria, eliminando las barreras que en la sociedad de acumulación de riqueza se levantan para las mujeres. Solo así se podrá garantizar la igualdad de oportunidades.

\footnotetext{
${ }^{6}$ Ibid., p. 234.

7 Ibid., p. 235.
} 


\section{Contra la visión monolítica de los feminismos. Clara Zetkin: "los intereses de las mujeres no son homogéneos"}

LAS FEMINISTAS DE LA DENOMINADA TERCERA OLA acusan al feminismo precedente de no tener en cuenta los diferentes intereses de las mujeres. Esta crítica, como hemos demostrado en otras investigaciones ${ }^{8}$, se basa en una visión distorsionada del feminismo precedente. Esta distorsión, lejos de ser inocente, se encuentra informada por el posfeminismo reaccionario que florece en los años 80 en Estados Unidos y encaja, sin demasiados problemas, con un feminismo que programáticamente se declara antiacadémico.

Desde entonces, es un lugar común negar el carácter calidoscópico que ha tenido el feminismo a lo largo de su propia evolución. La primera lección de diversidad nos la proporciona Clara Zetkin. La autora anticipa una de las tesis clave en la configuración del feminismo socialista, a saber, que "los intereses de las mujeres no son homogéneos, sino que están en función de su pertenencia a las diferentes clases sociales."

Siguiendo los análisis materialistas de F. Engels, nuestra autora considera que sólo es posible hablar de "cuestión femenina" en aquellas sociedades fruto del sistema de producción capitalista, por eso, no puede existir, por tanto, en la clase campesina ${ }^{10}$. Para Zetkin, la "cuestión femenina" se plantea para tres tipos de clases, a saber, las mujeres del proletariado, las de la pequeña-mediana burguesía y las intelectuales burguesas y por último, para las de la gran burguesía. Además, la "cuestión femenina" presentará "distintas características según la situación de clase de estos grupos." ${ }^{11}$ El propósito de la autora es mostrar las diferentes articulaciones que realiza cada clase.

Para Zetkin, las mujeres de la alta burguesía pueden desarrollar su individualidad, si bien, dependen del varón. Las uniones matrimoniales se producen sin amor, son acuerdos económicos y todos sus deberes como mujer, madre y esposa los traslada a terceras personas. Sus reivindicaciones se sitúan en reclamar su patrimonio, pues es aquello que le permite dar sentido a sus vidas. Las reivindicaciones de las mujeres de la alta burguesía se centran en conquistar sus derechos frente a los varones burgueses, de la misma forma que éstos, lucharon contra el Ancien

\footnotetext{
${ }_{8}$ Ávila Bravo-Villasante, María. La máquina reaccionaria. La lucha declarada a los feminismos, Valencia, Tirant Humanidades, 2019.

9 De Miguel Álvarez, Ana, "La articulación del feminismo y el socialismo: el conflicto clase-género" en Amorós, Celia y De Miguel, Ana, Teoría feminista: de la Ilustración a la globalización. Tomo 1, Madrid, Minerva Ediciones, 2010, p. 304.

${ }^{10}$ Zetkin, Clara. La cuestión femenina y el reformismo. Barcelona, Anagrama, 1976, p. 101.

11 Ídem., p. 101.
} 
Régime por la "abolición de todas las discriminaciones sociales basadas en el patrimonio." ${ }^{12}$

Las mujeres de la baja y media burguesía y las intelectuales burguesas tienen ante sí una problemática diferente. Mientras en la alta burguesía la propiedad y la familia se encuentran separadas, en la mediana y baja burguesía ambas son indisolubles. El régimen de producción capitalista está deteriorando la situación de los profesionales liberales, abocados a un proceso de proletarización. Los burgueses, cada vez más empobrecidos, no encuentran muchos alicientes para contraer matrimonio dado que, en parte, puede encontrar en el mercado todas las comodidades que le proporcionaría una esposa legítima.

El número de solteras entre la baja y media burguesía es cada vez mayor, por lo que sus demandas se centran en igualdad económica, igualdad a la que se accede reclamando educación profesional e igualdad en el acceso a los empleos. El aumento de la competencia es una de las grandes barreras con la que tienen que habérselas en sus solicitudes, encontrando amplio rechazo por parte de los burgueses. Pero, según Zetkin, sus demandas no sólo se centran en lo económico, alcanzan también el "aspecto moral y espiritual" en la medida que no sólo aspiran a ser independientes económicamente, reclaman para sí, como más tarde dirá Beauvoir, la transcendencia, la posibilidad de llevar a cabo sus propios proyectos vitales. Precisamente, dirá nuestra autora,

"es en estos estratos donde se encuentran aquellas trágicas figuras, tan interesantes desde el punto de vista psicológico, de mujeres cansadas de vivir como muñecas en una casa de muñecas y que desean participar en el desarrollo de la cultura moderna, las aspiraciones de las feministas burguesas están plenamente justificadas, tanto en el aspecto económico como desde el punto de vista moral y espiritual." ${ }^{13}$

Queda por analizar cómo articula la clase obrera la "cuestión femenina". El caso de las proletarias no tiene nada que ver con las anteriores clases sociales. Las obreras se ven arrastradas a la vida económica por el sistema de producción capitalista. Las primeras incursiones de las mujeres en la esfera económica respondían a un intento de suministrar un apoyo económico al marido, pero ha sido el propio sistema el que ha convertido este apoyo en competencia desleal. La mujer se ha convertido en una fuerza de trabajo igual a la de los hombres. Al ser una "fuerza de trabajo voluntaria" ${ }^{14}$, no suele oponer resistencia a la explotación capitalista. Las mujeres proletarias han entrado de pleno en el sistema y, si bien, disponen de independencia

\footnotetext{
12 Ibid., p. 102.

13 Ibid., p. 104.

14 Ídem., p. 104.
} 
económica, no ha conseguido ninguna ventaja, pues son castigadas doblemente: por el sistema patriarcal y por el sistema de producción capitalista. Su desarrollo individual, como mujeres, esposas y madres se ve frustrado, pues "para su tarea de mujer y madre sólo le quedan las migajas que la producción capitalista deja caer al suelo." 15

La lucha de las proletarias por su emancipación, no tendrán nada que ver con la de las burguesas. En su caso no se plantea como una lucha contra hombres de su misma clase, sino que la suya es la lucha de toda su clase contra los capitalistas, "la mujer proletaria, no necesita luchar contra los hombres de su clase" ${ }^{16}$ pues su objetivo no es la libre competencia, sino "la conquista del poder político por parte del proletariado." ${ }^{17}$

Pese a la diferente articulación de la "cuestión femenina" en las mujeres burguesas y en las proletarias, Zetkin no niega su apoyo al feminismo burgués. En el discurso que pronuncia en el Congreso de Gotha del Partido socialdemócrata alemán en 1896, anima a las proletarias a apoyar a las burguesas en sus reivindicaciones de igualdad política, si bien, advierte, la consecución de la igualdad política no cambiará las relaciones de clase.

\section{La prostitución como apéndice de la sociedad clasista y patriarcal: A. Kollontai}

Tomamos prestada una Reflexión de Ana de Miguel ${ }^{18}$ para ilustrar el siguiente debate. Si existe hoy en día una escuela de desigualdad, es la prostitución (correlato, a su vez, de otros sistemas de mercantilización de mujeres como es la pornografía). $\mathrm{Y}$ es una escuela de desigualdad en un doble sentido; por un lado, nos enseña que hay multitud de seres humanos que son susceptibles de ponerse en venta en el mercado. Huelga decir que estamos ante un fenómeno generizado en oferta (mujeres) y demanda (hombres). Por tanto, estamos ante un sistema desigual en el que persiste el sempiterno intercambio de mujeres. Por otro lado, es un sistema que perpetúa la desigualdad de clase. La amplia mayoría de mujeres en prostitución se encuentran en una situación de vulnerabilidad extrema.

Desde sus inicios ilustrados, el feminismo ha sido muy crítico con la prostitución de mujeres, supo ver con claridad que se trataba de un sistema de esclavitud

\footnotetext{
15 Ibid., p. 105.

16 Ídem., p. 105.

17 Ídem., p. 105.

${ }^{18}$ De Miguel Álvarez, Ana, “La prostitución de mujeres, una escuela de desigualdad humana”, en Revista Europea de Derechos Fundamentales, Núm., $191^{\text {er }}$ Semestre 2012, pp. 49 - 74.
} 
al que se veían abocadas las mujeres ante la falta de otras opciones. El análisis de Alejandra Kollontai apunta en esta dirección.

Para Kollontai, la prostitución es un apéndice de la sociedad clasista contemporánea; no sólo es clasista. Paradójicamente, será promovida por los mismos que ensalzan los valores familiares. Es precisamente entre el proletariado donde la prostitución causa verdaderos estragos, pues son los cuerpos de las proletarias, bajo la más cruel de las coerciones — la necesidad y el hambre - los que serán vendidos como mercancías. En la medida en que se alimenta de las proletarias, los burgueses se muestran tolerantes, aunque podríamos suponer una actitud muy distinta por su parte si la mayor parte de las prostitutas fueran burguesas.

Aunque existen prostitutas entre las clases burguesas, sus situaciones no tienen nada que ver con las prostitutas de la clase obrera. Para empezar, las propias instituciones médico-policiales suelen hacer la vista gorda a la prostituta "de altos vuelos", descargando toda su violencia sobre las prostitutas de clase obrera, que serán doblemente victimizadas. Los burgueses, desde su falsa "pureza moral", acusarán a estas mujeres de "ultrajar las virtudes" y pondrán todo su empeño en amargarles la existencia. Para ello tienen a su servicio a las instituciones, que someterán a duros reconocimientos a aquellas mujeres que consideren prostitutas. Huelga decir, como nos recuerda Kollontai, que esta "consideración" se extiende a muchas de las mujeres proletarias, "sobre todo para las que viven en las afueras. Sin mencionar siquiera los períodos de paro crítico, en los cuales la mujer está por supuesto en la calle 'sin razones plausibles"' 19 .

Para Kollontai, no serán las "amaneradas resoluciones de las feministas" ${ }^{20}$ las que pondrán fin a la prostitución. Es necesario un cambio en la relaciones económicas, sociales y jurídicas; y ese cambio, es una tarea de la clase obrera.

Uno de los aspectos más novedosos que establece Kollontai al abordar el tema de la prostitución, es la "deformación de la psicología humana". Para nuestra autora, la prostitución sería una "escuela de desigualdad" que afectará a la reciprocidad sexual que se establece en el seno mismo de las relaciones íntimas. Como ha señalado Ana de Miguel, Kollontai anticipa varios temas que tendrán que esperar hasta los años sesenta para poder abordarse abiertamente; así, "no sólo denuncia explícitamente el desconocimiento por parte de los varones de la sexualidad femenina, sino que acusa explícitamente a la literatura masculina de silenciar dicha insatisfacción aún cuando es la clara causa de incontables dramas de 'familia y amor"' ${ }^{21}$.

19 Kollontai, Alejandra. Marxismo y Revolución Sexual., op. cit., p. 37.

${ }^{20}$ Ibíd., p.38.

${ }^{21}$ De Miguel Álvarez, Ana, “La articulación del feminismo y el socialismo: el conflicto clase-género” en op.cit. p. 318. 
Kollontai analiza los efectos de la prostitución en la psicología masculina. La prostitución sería una escuela de desigualdad en tanto que acuden a ella para satisfacer sus deseos, sin tener en cuenta los deseos y sentimientos de las mujeres. Reciben placer, sin importarles que sea un acto forzado y omiten la regla fundamental de la reciprocidad. En palabras de la autora:

"La falta de costumbre de los hombres para preocuparse de la psicología de las mujeres, de sus sentimientos, no aparece únicamente en la incapacidad de prestar atención al alma de las mujeres, sino que, aún más, lleva a los hombres a ignorar, con sorprendente ingenuidad, las sensaciones fisiológicas de la mujer en el acto más íntimo"22.

El consumo de prostitución no sólo los lleva a desoír los deseos morales o anímicos de las mujeres, los lleva, además, a ignorar sus deseos sexuales. Esta psicología simplista de los hombres es una fuente inagotable de dramas, que afectará por igual a las mujeres casadas o mujeres que conviven en uniones libres, al saltarse la regla fundamental de la reciprocidad. Cuanto más "nueva" es la mujer, esto es, cuánto más alta es su individualidad, más agudo se hace su sentimiento de insatisfacción (psíquico y sexual). Por eso, es fundamental abordar el tema de la prostitución no sólo desde una perspectiva fisiológica —enfermedades, debilitamiento de la especie- hay que prestar, sobre todo, atención al factor psicológico. La prostitución, dirá nuestra autora, "ensombrece los impulsos morales, aherrumbrando y deformando la conciencia erótica, y haciendo que el hombre y la mujer se comprendan menos cada vez, sepan menos amarse mutuamente sin abusar el uno del otro" ${ }^{23}$.

En 1917, la feminista judía de origen austriaco Grete Meisel-Hess publica La crisis sexual. El libro, causó una gran fascinación en Kollontai, que llegó a afirmar que "el mérito de Meisel-Hess es el mismo que el del niño del cuento de Andersen: se atreve a gritar a la sociedad con tranquilo valor que "el rey no lleva camisa", que la moral sexual contemporánea no es sino una ficción hueca" 24 .

La moral sexual, a juicio de Kollontai, está ligada a los intereses de la clase dominante, esto es, están al servicio de la propiedad privada, lo que impide que esté al servicio de los objetivos para los que una moral sexual es legítima, a saber, conseguir una descendencia sana, y el crecimiento psicológico de los seres humanos y fomentar en la humanidad sentimientos de solidaridad y camaradería.

Lejos de servir a alguno de esos propósitos, la moral sexual burguesa aboca a la humanidad a la absoluta degeneración. Los cada vez más tardíos matrimonios, la prostitución -que arrastra a sus filas a las mujeres más bellas- y los matrimonios

\footnotetext{
${ }_{22}$ Kollontai, Alejandra. Marxismo y Revolución Sexual., op. cit., p. 131, nota 84.

23 Ídem., p. 131.

24 Ibíd., p. 126.
} 
de conveniencia -de los que sólo es posible esperar una descendencia afectada del carente éxtasis amoroso de sus padres- hacen que el futuro físico, psíquico y moral de la humanidad esté seriamente comprometido.

\section{Sylvia Pankhurst. La opresión es interseccional}

¿Cómo es esa Mujer nueva en el pensamiento de Sylvia Pankhurst? Vemos que se trata de una mujer que trabaja y lucha por cambiar una sociedad basada en la opresión, rechaza la doble moral sexual, y persigue relaciones igualitarias en la que se respete su autonomía como mujer libre y como madre si así lo desea. Pero no se trata de ninguna abstracción, ya que las mujeres deben ser conscientes de las opresiones a las que están sujetas; de clase, género, etnia etc.

En las últimas décadas la categoría analítica desarrollada por K. Crenshaw, la interseccionalidad ${ }^{25}$, ha sido muy utilizada sobre todo en las ciencias sociales, aunque también en el derecho e incluso en la psicología. Así, las mujeres, estarían sujetas a distintos sistemas de discriminación -por género, clase, raza- interconectados que podemos estudiar no solo en cuanto a lo estructural sino también en lo político y en lo representacional. Autoras como A. Davis ya sitúan los escritos sobre la 'triple opresión' a finales de los años sesenta ${ }^{26}$. En este sentido, la figura de la sufragista y socialista Sylvia Pankhurst resulta clave para iluminar el oscuro túnel de la invisibilización y la distorsión existente respecto a las ideas feministas del siglo XIX.

Sylvia Pankhurst, hija de la carismática líder sufragista Emmeline Pankhurst, y heredera de la tradición ilustrada y de reforma social que caracterizó el siglo XIX en Inglaterra, forma parte de un movimiento político y social de masas, el sufragismo. Tanto sus escritos como su práctica política recogen una crítica a las diferentes formas de injusticia, a las diferentes opresiones que padece el ser humano. Las mujeres son oprimidas por su sexo en todas las clases sociales pero las trabajadoras lo serán también por su clase. Pero si además han nacido en un territorio colonizado y/o pertenecen a una raza no blanca, lo serán mucho más. Pankhurst es sensible a esta multitud y superposición de opresiones. Las describe, denuncia e incorpora a su pensamiento.

Si bien el sufragismo se caracteriza por su heterogeneidad -no todas las autoras y militantes abrazan todas las mismas ideas y luchas-, existen antecedentes desde los

\footnotetext{
${ }^{25}$ Crenshaw, Kimberlé "Demarginalizing the Intersection of Race and Sex: A Black Feminist Critique of Antidiscrimination Doctrine, Feminist Theory and Antiracist Politics”, University of Chicago Legal Forum, 1, 1989, pp. 139-167.

26 Davis, Angela Y., Mujeres, raza y clase, Madrid, Akal, 2004.
} 
inicios del mismo en torno a la lucha por la abolición de la esclavitud. Las mujeres esclavizadas en Norteamérica conocieron la solidaridad de mujeres feministas como fue el caso de las comprometidas con el Underground Railroad, una ruta clandestina de huida de personas negras hacia territorio seguro durante la primera mitad del siglo XIX. Empatía, solidaridad y una firme creencia en la universalidad de los derechos de todas las mujeres, de todas las personas, guiaban su compromiso.

A lo largo de su vida Pankhurst vuelca su experiencia social y militante en sus escritos periodísticos, memorias y obras, aportando interesantes análisis a los debates género-clase. Como feminista y socialista critica los pactos interclasistas entre varones, señalando que empresarios y sindicalistas coinciden negando a las mujeres trabajadoras el derecho a la igualdad salarial y el acceso al trabajo cualificado; o también que los hombres se benefician del trabajo no remunerado de las mujeres o de su falta de formación. Es capaz de identificar contradicciones y de conectar las diferentes opresiones con audacia. Dedica un esfuerzo considerable a intentar convencer a las organizaciones socialistas y comunistas para que asuman las reivindicaciones igualitarias de las mujeres en su proyecto de transformación social. De igual modo, trata de reforzar el enfoque de clase en el seno del movimiento de mujeres del que forma parte. ${ }^{27}$

Como antirracista y anti-colonialista, sus posiciones son pioneras ya que ni siquiera en el ámbito de la izquierda británica de su tiempo existe una aceptación clara de los presupuestos contrarios a la discriminación sexual y racial, estando imbuida de una cierta ideología pro-imperialista y de superioridad racial. Pankhurst es conocedora de las posiciones de los militantes radicales negros o asiáticos de las colonias, y comprende el vínculo existente entre las actitudes racistas y los intereses económicos de las potencias europeas en estos países. Por ello, denuncia los abusos y la explotación llevados a cabo en los países colonizados y apuesta por la solidaridad internacionalista entre las personas oprimidas de distintas naciones. Trata de concienciar a hombres y mujeres trabajadores para que identifiquen los intereses capitalistas y patriarcales como sus verdaderos enemigos, independientemente de su raza, nacionalidad o cultura:

"El partido laborista no ha apoyado la lucha por la democracia y la libertad en India... La mayoría de los líderes sindicales son abiertamente pro-imperialistas. Aunque sus bases están parcialmente concienciadas de que el imperialismo es algo que beneficia a sus amos, no se dan cuenta de hasta qué punto está íntimamente ligado a su propio sometimiento por parte del sistema capitalista." 28

\footnotetext{
27 Palomo, Eva. Sylvia Pankhurst. Sufragista y socialista, Castilla-La Mancha, Almud, 2015.

28 Pankhurst, Sylvia. India and the Earthly Paradise, Bombay, Sunshine Publishing House, 1926, pp. 329-330.
} 
Autoras como A. Burton han analizado la existencia de prejuicios colonialistas dentro del sufragismo, concluyendo que a pesar de las distintas posiciones al respecto el programa feminista se basaba en la idea de que la opresión de la mujer era universal, trascendiendo fronteras nacionales y raciales, y de que las mujeres en todo el mundo compartían una condición similar en su opresión como tales. ${ }^{29}$ Sabemos que esta idea fue ampliamente discutida en las últimas décadas del siglo XX, sobre todo en el contexto de los llamados feminismos post-coloniales. ${ }^{30}$

Sylvia Pankhurst nunca mantiene una postura eurocéntrica, sino que estudia las particularidades que caracterizan la situación de las mujeres y de la población excluida en otras culturas, defendiendo unos derechos universales que distan mucho de caer en posiciones relativistas:

"A menudo, los reformadores atacan el abuso de forma selectiva mostrando un respeto puntilloso por otros que ejercen un mal muy similar al que habitualmente están intentando combatir. Esto constituye una traición a la mejora del bienestar general. En occidente solemos encontrar fervorosos demócratas y laboristas cuyos principios sólo son aplicables a su propia clase, gremio, sexo o raza. En India encontramos nacionalistas que demandan la abolición de la exclusión racial impuesta por los europeos, pero son los máximos defensores de la discriminación de casta y de sexo." ${ }^{31}$

Pankhurst denuncia las distintas discriminaciones allá dónde se producen, en su país, en los países que visita y también en las colonias. Ser anti-colonialista, anti-imperialista y anti-racista no le impiden criticar prácticas misóginas: “... nos oponemos a las divisiones de casta en relación al matrimonio, al matrimonio infantil y a la organización de los casamientos por parte de otros que no sean los interesados, la compra de novias o la prohibición de volver a casarse que pesa sobre las viudas" 32 . En este sentido coincide con autoras feministas muy posteriores, como la egipcia Nawal Al-Sadawi quien no duda en denunciar costumbres patriarcales en su propia cultura, siendo su posición claramente anti-colonialista y de clase:

\footnotetext{
${ }^{29}$ Burton, Antoinette "The feminist quest for identity; British Imperial Suffragism and Global Sisterhood 19001915”, Journal of Women's History, vol. 3, no 2, 1991, p. 49.

30 Para profundizar en los diferentes enfoques sobre esta cuestión, ver María Luisa Femenías, "El Feminismo Postcolonial y sus límites", en Celia Amorós y Ana de Miguel (Eds.), Teoría feminista: de la Ilustración a la globalización, T. 3, Madrid, Minerva Ediciones, 2010, pp. 153-264; Roldán, Concha, “¿Quién le cuelga la responsabilidad a la justicia?” Lectora: revista de dones i textualitat, no. 9, 2003, pp. 45-56; Valcárcel, Amelia. Ética para un mundo global. Una apuesta por el humanismo frente al fanatismo, Madrid, Temas de hoy, 2002. Cfr. Chandra Mohanty, “'Under Western Eyes': Feminist Scholarship and Colonial Discourse”, Feminist Review, 30 (Autumn), 1988, pp. 61-88; Chandra Mohanty, e Ibid. "De vuelta a 'Bajo los ojos de occidente': La solidaridad feminista a través de las luchas anti-capitalistas”, en Liliana Suárez y Rosalva A. Hernández (Coords.), Descolonizando el Feminismo: Teorías y Prácticas desde los Márgenes, Madrid, Cátedra, 2008, pp. 407-466.

31 Pankhurst, Sylvia. India and the Earthly Paradise, op.cit, pp. 162-163.

32 Ibid., pp. 165-166.
} 
"La dignidad no existe cuando se transforma a un ser humano en instrumento, objeto o mercancía. Las costumbres y leyes en nuestra sociedad patriarcal y de clases son la negación misma de la verdadera dignidad, pues transforman a la mujer en una mercancía que se cambia por una dote y se vende por una pensión alimenticia. A veces, puede incluso llegar a venderse por nada". ${ }^{33}$

Con toda seguridad, Pankhurst habría compartido la aguda reflexión de la filósofa española Celia Amorós acerca del derecho a interpelar cualquier cultura desde el género: "Así, las feministas deberíamos poner en cuestión todas las reglas de todas las tribus. Incluida la nuestra, por supuesto. Ya lo hemos hecho: hemos ilustrado a nuestra Ilustración en sus puntos ciegos con respecto a las mujeres." 34

\section{Conclusiones}

EN ESTE TRABAJO SE HA REFLEXIONADO acerca de la importancia de las aportaciones que nos han legado diversas autoras pertenecientes a la tradición del pensamiento feminista y socialista. El conocimiento de sus ideas sobre qué significaba ser mujeres en su tiempo y qué debía significar-La Mujer nueva-, ciertamente arroja luz a la hora de abordar muchos de los debates actuales en el seno del feminismo tanto en el ámbito académico como en el social. Es necesario seguir profundizando en el análisis de las contribuciones de las autoras estudiadas, que el androcentrismo ha minimizado a lo largo de la historia, y que aún en el presente continúan siendo objeto de invisibilización y distorsión. Pensamos que no deben caer en el olvido ya que su papel es importante para la filosofía moral y política de los dos últimos siglos y clave para el avance de la igualdad.

Al-Sadawi, Nawal. La cara oculta de la mujer árabe, Madrid, Horas y horas, 1991, p. 79.

34 Amorós, Celia, "Feminismo y Multiculturalismo", en Celia Amorós y Ana de Miguel (Eds.), Teoría feminista: de la Ilustración a la globalización, T. 3, Madrid, Minerva Ediciones, 2010. p. 233. 


\section{REFERENCIAS BIBLIOGRÁFICAS}

Al-Sadawi, Nawal. La cara oculta de la mujer árabe, Madrid, Horas y horas, 1991.

Amorós, Celia. "Feminismo y Multiculturalismo", en Celia Amorós y Ana de Miguel (Eds.), Teoría feminista: de la Ilustración a la globalización, T. 3, Madrid, Minerva Ediciones, 2010.

Arruza, Cinzia; Bhattacharya, Tithi y Fraser, Nancy. Manifiesto de un feminismo para el 99\%, Barcelona, Herder editorial, 2019.

Ávila Bravo-Villasante, María. La máquina reaccionaria. La lucha declarada a los feminismos, Valencia, Tirant Humanidades, 2019.

Burton, Antoinette. "The feminist quest for identity; British Imperial Suffragism and Global Sisterhood 1900-1915", Journal of Women's History, vol. 3, no 2., 1991, pp. 46-81. https://doi.org/10.1353/jowh.2010.0098, 1991.

Crenshaw, Kimberlé. "Demarginalizing the Intersection of Race and Sex: A Black Feminist Critique of Antidiscrimination Doctrine, Feminist Theory and Antiracist Politics", University of Chicago Legal Forum, 1, 1989. pp. 139-167.

Davis, Angela Y. Mujeres, raza y clase, Madrid: Akal, 2004.

De Miguel Álvarez, Ana. "La articulación del feminismo y el socialismo: el conflicto clase-género" en Celia Amorós y Ana de Miguel (Eds.), Teoría feminista: de la Ilustración a la globalización, T. 1, Madrid, Minerva Ediciones, 2010.

De Miguel Álvarez, Ana. "La prostitución de mujeres, una escuela de desigualdad humana", en Revista Europea de Derechos Fundamentales, Núm.,19 1er Semestre 2012, pp., 49-74, (2012)

Femenías, María Luisa. "El Feminismo Postcolonial y sus límites", en Celia Amorós y Ana de Miguel (Eds.), Teoria feminista: de la Ilustración a la globalización, T. 3, Madrid, Minerva Ediciones, 2010.

Kollontai, Alejandra. Marxismo y Revolución Sexual. Madrid, Castellote, 1976.

Mars, Amanda. "Charlene A. Carruthers. 'Acabar con el capitalismo es un asunto feminista”, El Pais 15/12/2019. Disponible en https://elpais.com/elpais/2019/12/13/ideas/1576257797_678594.html

Mohanty, Chandra. “'Under Western Eyes' Feminist Scholarship and Colonial Discourse", Feminist Review, 30 (Autumn), pp. 61-88. https://doi.org/10.1057/ fr.1988.42, 1998. 
Palomo, Eva. Sylvia Pankhurst. Sufragista y socialista, Castilla-La Mancha, Almud, 2015

Pankhurst, Sylvia. India and the Earthly Paradise, Bombay, Sunshine Publishing House, 1926.

Roldán Panadero, Concha. “QQuién le cuelga la responsabilidad a la justicia?" Lectora: revista de dones $i$ textualitat, $\mathrm{n}^{\circ}$. 9, 2003, pp. 45-56. Disponible en: https://www.researchgate.net/publication/49112354_Quien_le_cuelga_la_responsabilidad_a_la_justicia. 2003.

Thompson, William y Wheeler, Anna. La demanda de la mitad de la raza humana, las mujeres contra la pretensión de la otra mitad los hombres, de mantenerlas en la esclavitud politica y, en consecuencia, civil y doméstica. Granada, Comares, 2000.

Valcárcel, Amelia. Ética para un mundo global. Una apuesta por el humanismo frente al fanatismo, Madrid, Temas de hoy, 2002.

Waithe, M. Ellen. History of Women Philosophers. Vol. III. Dordrecht, Kluwer Academic Publishers, 1991.

Zetkin, Clara. La cuestión femenina y el reformismo, Barcelona, Anagrama, 1976.

DOI: https://doi.org/10.15366/bp2021.27.011

Bajo Palabra. II Época. No 27. Pgs: 213-230 
